Education, Gwalior, were randomly divided in two groups, that is, experimental and control group. The age of subjects varied between 18 and 22 years. The criterion measures vertical jump, 20-m dash, movement speed, flexibility and agility in the beginning and at the end of the experimental period of 6 weeks for both the groups. In order to study the effect of plyometric exercises on selected motor abilities, the analysis of co-variance is used at the 0.05 level of significance. It was concluded that the plyometric training is an effective means for improving the following variables: agility, flexibility vertical jump and movement speed. On the other hand, plyometric training is not an effective means for improving the variable, that is, speed of movement (20-m dash). There was no significant improvement in case of control group.

\title{
75 EFFECTS OF PLYOMETRIC EXERCISES ON SELECTED MOTOR ABILITIES OF UNIVERSITY LEVEL FEMALE BASKETBALL PLAYERS
}

Chetna Chaudhary, ${ }^{1}$ Birendra Jhajharia ${ }^{2}{ }^{1}$ Banasthali Vidhyapeeth, Banasthali, Rajasthan, India; 'Lakshmibai National University of Physical Education, Gwalior, Madhya Pradesh, India

10.1136/bjsm.2010.078725.75

Today there is not a single sport in the world at the competitive level for which resistance training in some or the other form is not used as conditioning exercises. Plyometric training is an excellent method of developing body power and it is proved as a very effective method for improving explosive strength. The purpose of the study was to find out the effects of plyometric exercises on selected motor abilities of university level female basketball players. The subjects, 20 female basketball players of Lakshmibai National Institute of Physical 